\title{
Understanding Learners' Perspective on Creative Music Making
}

\author{
Dr. Durgesh K. Upadhyay *
}

\section{ABSTRACT}

Creative music making is one of the least studied aspects of music education. This may be partly due to our limited knowledge of the creative process. There is a need to explore and understand the creative process of music making by taking perspective of music students within a particular socio cultural context. Present study aimed to explore and analyze the creative process of music making (making variations in rāga's contents and/or compositions) by considering the vocal students' perspective in an institutional setup. 10 vocal students (2 from Diploma, 4 from B. Mus. and 4 from M. Mus.) from two prestigious institutions of UP were interviewed (4 in-person and 6 telephonically). Thematic analysis revealed three themes - causal forces, conscious music making, and natural process of music making. Findings suggest that the particular psychological state, occasion or situation which inspires music students to visualize and forces them to create new music. Two creative processes of music making identified (i.e., conscious and natural) follow different pathways.

Keywords: Hindustani music; creative process; sociocultural context; rāga

\section{INTRODUCTION}

Running (2008) noted that a large body of research regarding creativity and music education has focused more on measuring musical creativity than on creative process. The creativity literature has primarily relied on the 4P model of Rhodes (1961) which embraces four independent factors-person, process, product and press. Every person has creative potential but has different ways of expressing it. There is a constellation of other relevant factors, including motivation, personality, traits, skills and knowledge for creativity to manifest. Process refers to stages or manner in which creativity unfolds. Product is the output of the creative process (music performance) and press refers to the context within which creativity manifests. Panda (2011) has reviewed Indian studies on creativity along the four major aspects: person, place, process, and product, though she did not deal with musical creativity per say.

Many of the creativity research usually decontextualise creative people, processes and products (Lubart, 1999); whereas, contextualises advocate that context have certain affect on creativity. Context refers to the set of facts or circumstances that surround a situation or event. It may assimilate in itself the culture, personal and social factors, and the works and practices of a culture. Bhawuk (2003) proposed that cultures moderate the channelling of individual abilities toward certain creative behaviors.

* Learners' Perspective on Creative Music Making, AIBAS, Amity University, Uttar Pradesh, Gomti Nagar Extn., Near Malhaur railway Station, Lucknow - 226028 (India)

(C) 2014 D Upadhyay; licensee IJIP. This is an Open Access Research distributed under the terms of the Creative Commons Attribution License (http://creativecommons.org/licenses/by/2.0), which permits unrestricted use, distribution, and reproduction in any Medium, provided the original work is properly cited. 


\section{Understanding Learners' Perspective on Creative Music Making}

Research has evinced the importance of personal and societal factors while examining a specific case of creative process (Newman, 2008). According to Indian perspective, creativity depends on the culture of the country (desha), the historical era in which one lives $(k \bar{a} l a)$, on the efforts required (śrama) and, lastly, on one's innate character (guna) that is probably inherited from past lives (Kakar and Kakar 2007).

"Creativity" is not a useful term because it is so misused (See Webster, 2002). For many years, Webster maintained that "creative thinking" is really a term that has its base in what most of us understand to be "creativity." What creativity in music really is: the engagement of the mind in the active, structured process of thinking in sound for the purpose of producing some product that is new for the creator? This study takes forward the assumption made by Webster (2002). Webster conceptualises creative thinking as a dynamic process of alternation between convergent and divergent thinking, moving in stages over time, enabled by certain skills (both innate and learned), and by certain conditions, all resulting in a final product. Creative thinking is not always a mysterious process that is based on divine inspiration or reserved only for those who are labelled as "gifted" or "genius." Creative thinking also occurs at various levels, from the spontaneous songs of the very young child to the products of the greatest minds in music.

Odena (2002) aptly explained two opposing views among people regarding the general understanding of creativity in music: the systematic and the romantic. The systemic view involves a good deal of effort and persistence (conscious efforts), where creative work is seen as a rational everyday affair. This is in opposition to the romantic view of creativity characterized by irrationality, mystery and unconsciousness (natural). However, a relevant idea for developing creativity in music is that a period of focused effort is required in order to have an in depth understanding of music-related issue.

The term 'music making' as used in this research has been considered synonymous to 'making composition'. Barrett (2003) described music making as using "the basic properties of sound, such as length, volume and timbre or tone colour" and refining or combining these "to create musical meaning" (p. 65). Hickey (2002) noted that creative music making is one of the least studied aspects of music education. This may be partly due to our limited knowledge of the creative process (Hickey, 2001; Sloboda, 1985). Be ghetto and Kaufman (2007) and Kaufman, Baer, and Cole (2007) are the few who made endeavours in this direction by looking at selfperceptions of creative individuals. How do students and experts view their own creativity? There is a need to explore and understand the creative process of music making by taking perspective of music students within a particular sociocultural context.

Numerous available biographies and autobiographies of Indian musicians are also lacking the process contents. In fact one can find few biographies and autobiographies (like Bhimsen Joshi: A Passion for Music by Majumdar, 2004) talking about the learning/training process to some extent but they rarely talked about creative processes. Even if it has been mentioned somewhere, it seems like introducing the terms rather defining or explaining. The present study, following this line of thinking has focused on creative process of music making by taking the perspective of music (vocal) students belonging to Hindustani music tradition.

In Hindustani music system - which is based on melody-single notes played in a given order (horizontal system) (Weber, 1976, p. 297) - where the grammar of melody and rhythm is fixed, the skill and ingenuity of the musician lies in his improvisation and creativity, especially in 
evocation of the mood and rasa of the particular rāga. A rāga is the combination of different notes that contained in an octave, with varnas that pleases the listeners (Bandopadhyay, 1995, p. 55). The greatest strength of Hindustani music is that it enjoys the freedom to experiment in both theme and practice (Mansukhani, 1982). The objective for the singer is to express himself through music making and to share with the listener all phases of the creative process, much as an idea developed in extempore speech (Dhar, 2005, p. 221). Dhar further pointed that Hindustani tradition offers extraordinary freedom to musicians to express their being. They can freely explore the areas in between the rigid 'notes' of the keyboard and free from objective time (p. 223).

Hindustani music tradition acknowledges two kind of creation - 'improvisation' and 'compositions.' A composition means a bandiśa, which is a definite arrangement of words into notes and rhythm. On the other hand, improvisation, which takes place during practice, refers to the other parts of a rāga performance, such as ālāpa, tāna etc. In composition, changes (in relation to àlāpa, baìdiśa, baŗhata, layakārī, bolbanāo and tāna) are done meditatively, worked out in practice (Meer, 1980).

\section{MODELS OF CREATIVE PROCESS}

More than two decades ago, Keating (1980) said that there is no clear, unambiguous and widely accepted definition of the creative process. Lau (2006) wondered that this view continues to be held even today. He said that because of the multifaceted nature of creative processes, various strands have been used to explore the concept. Plsek (1996) noted that some experts dismissed the notion that creativity could be described as a sequence of steps in a model. For example, Gestalt philosophers like Wertheimer (1945) asserted that the process of creative thinking as an integrated line of thought that does not lend itself to the segmentation implied by the steps of a model. In a similar vein, Vinacke (1953) was adamant that creative thinking in the arts does not follow a model. Nevertheless, Plsek (1996) concluded that while such views are strongly held, they are in minority.

From a psychological perspective, Arasteh and Arasteh (1976) regarded creative processes as including imagination, fantasy, originality, divergent thinking, inventiveness, intuition, ingenuity, innovation, venturesomeness, exploration, curiosity, discovery learning and problem solving. Wright (2003) described an equally complex list of creative processes, which include fluency, flexibility, elaboration, transformation, problem solving, objectivity, and selectivity, and aesthetic and practical standards.

In his book Creativity: The Magical Synthesis, Silvano Arieti (1976) catalogued eight models of the creative thinking process that were proposed during the period 1908 to 1964. Additional models have been proposed since. One of the earliest models of the creative process is attributed to Graham Wallas. Wallas (1926) proposed that creative thinking proceeds through four phases: preparation (definition of issue, observation, and study), incubation (laying the issue aside for a time), illumination (the moment when a new idea finally emerges) and verification (checking it out). Torrance (1988) asserts that Wallas' model is the basis for most of the creative thinking training programs available today. The implied theory behind Wallas' model -- that creative thinking is a subconscious process that cannot be directed, and that creative and analytical thinking are complementary -- is reflected to varying degrees in other models of creativity. 
Rossman (1931) examined the creative process via questionnaires completed by 710 inventors and expanded Wallas' original four steps to seven. These steps are - (a) observation of a need or difficulty; (b) analysis of the need; (c) a survey of all available information; (d) a formulation of all objective solutions; (e) a critical analysis of these solutions for their advantages and disadvantages; (f) the birth of the new idea -- the invention; and (g) experimentation to test out the most promising solution, and the selection and perfection of the final embodiment. Note that while Rossman still shrouded the "birth of the new idea" in mystery, his steps leading up to and following this moment of illumination were clearly analytical.

Alex Osborn (1953), the developer of brainstorming, embraced a similar theory of balance between analysis and imagination in his seven-step model for creative thinking. These steps are orientation (pointing up the problem), preparation (gathering pertinent data), analysis (breaking down the relevant material), ideation (piling up alternatives by way of ideas), incubation (letting up, to invite illumination), synthesis (putting the pieces together), and evaluation (judging the resulting ideas).

Barron (1988) placed great emphasis on subconscious and chance processes in his four - phase "psychic creation model": conception (in a prepared mind), gestation (time, intricately coordinated), parturition (suffering to be born, emergence to light), and bringing up the baby (further period of development). The tone of Barron's model supports the popular view of creativity as a mysterious process involving subconscious thoughts beyond the control of the creator.

Plsek (1996) proposed the Directed Creativity Cycle; a synthesis model of creative thinking that combines the concepts behind the various models proposed over the last $80+$ years, some of them have been outlined previously. Directed creativity simply means that we make purposeful mental movements to avoid the pitfalls associated with our cognitive mechanisms at each step of this process of searching for novel and useful ideas.

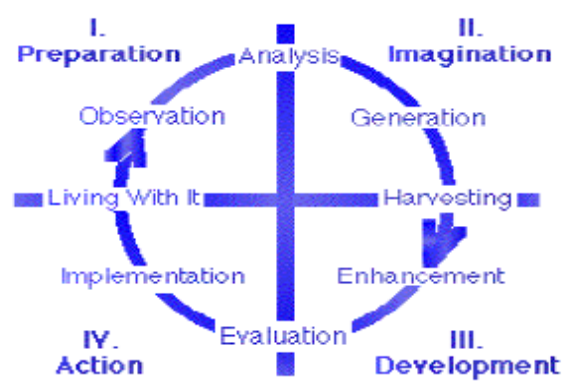

Upadhyay (2013) in his doctoral work found that there are two general processes of making variations - one is through conscious efforts and second is Natural, which has been also discussed by Meer (1980). Conscious process is the process when one intentionally makes an effort to create some music or variations in any rāga. Meer (1980) calls them the meditated changes, worked out in practice, which constitute a lapsus memoriae. On the other hand, Natural process is the process that does not have conscious steps. Subconscious changes or variations emerge naturally when a musician practices, a teacher teaches or a performer performs.

Jan Mittelstaedt, NCTM in his paper titled "Steps in the Creative Process" described the process of making of a composition. Mittelstaedt (1995) said that the evolution of a musical composition may be a lengthy or brief process and for some composers, ideas, which do not need revision, seem to flow quickly and freely. Mittelstaedt believed that composers who write freely and easily like Mozart (he wrote three symphonies in one summer, 1788) and those who, like Beethovan, compose with effort go through similar steps in their creative process. These steps 
include having a reason for the composition, getting an idea, planning the composition, writing the details, and critically evaluating and editing the final product. Mittelstaedt (1995) further noted that although a person with a knowledge of music can follow the outlined steps and create a composition, the piece will be dull and uninteresting if inspiration is absent.

Continued review of definitions of creativeness in both the general and music literature reveals five common elements: (1) a problem solving context, (2) convergent and divergent thinking skills, (3) stages in the thinking process, (4) some aspect of novelty, and (5) usefulness of the resulting product. Regardless of the discipline, most experts agree that creative thinking is driven by a problem and a need for its solution. In the arts, the problem is more a "force" in the creator that inspires or drives the creative spirit. In music, the response to this force is embodied in (a) composition, (b) performance/improvisation and (c) listening and analysis. (Webster, 2002)

Against this backdrop, present research has tried to propose tentative models of the creative processes of music making (conscious and natural) in the light of models proposed by Wallas and Osborn. The idea was not to test these models but to take their help in analyzing the successive steps followed by music students to create their own music. I personally convinced with what Plsek (1996) asked us to notice that these models clearly support the notion that innovation is a step beyond the simple generation of creative ideas. The action phase of the model makes it clear that creative ideas have value only when they are implemented in the real world (context).

\section{METHOD}

Present study aimed to explore and analyze the creative process of music making (making variations in rāga's contents and/or compositions) by considering the vocal students' perspective in an institutional setup. The Hindustani music in major North Indian government institutions is being taught through three back-to-back courses namely Diploma (3 years), Graduation (3 years), and Post Graduation (2 years). 10 vocal students (2 from Diploma, 4 from B. Mus. and 4 from M. Mus.) from two prestigious institutions of UP were interviewed (4 in-person and 6 telephonically). These students were among the participants of my doctoral work on which a questionnaire was administered. This questionnaire consisted questions related to creative music making. I had selected these students based on their response to the items of creative music making and on their desire to elaborate upon the creative processes in-person.

All the participants had given their contact numbers. I directly called and talked to them through mobile phone. Firstly, they were briefed about the context and purpose for calling. After their consent for interviews, they were asked to give time as per their comfort. With the second talk, interviews were started. On an average interviews were completed in 30 minutes. Students were asked to recall their creative experiences of making a composition or making of variations in a rāga's content. Further, they were asked whether these variations emerged naturally, or through conscious efforts and what was the process. Data obtained were recorded, transcribed and thematically analyzed. Analysis revealed three themes - causal forces, conscious music making, and natural process of music making. Emerged themes have been discussed in the following paragraphs. 


\section{Understanding Learners' Perspective on Creative Music Making}

\section{RESULTS AND DISCUSSION}

Causal Forces - These students recalled several factors that inspire creative thinking and which gets its expression through one's mother tongue. Anuragi shared:

Words come in mother tongue. It automatically pumps out through emotions, which may be yielded by immediate environment or people surrounded.

Namita clearly stated that she is normally guided by her mood. The particular psychological state provides a favourable atmosphere in which new music emerges. Namita gave her own example when she got heart attack and created her own music. Creativity may also be triggered by a particular situation or an occasion. Urvashi clarified further:

...in a particular mood, like when I am very sad, as I told. If I am a vocal student then some Dhun (tune) will come to my mind. Even when I am crying. Once I will stop, it becomes apparent.

Creativity manifests itself while practicing. Deepika indicated about riāz:

Suppose you are singing a Rāga or Bañdiśa and one Boltāna or Dhun emerges. It happens during riāz and even while sitting and singing without any purpose. Sometimes it comes up suddenly and sometimes it requires effort.

Deepika affirmed to the extent that riāz is the only source for creation. Avantika had the view that creativity becomes visible when one is talented, does rigorous riāz, and is blessed by his Guru. She expressed:

Guru is the gist of everything. He shows the path, but we should follow it all the way.

Urvashi emphasised upon the mutual learning between teacher and students. She explained this idea further -

My teacher motivates me to create. She says that sometimes I also learn from my students. Any art of the world is nothing but learning and teaching. No artists are perfect. For few things he gets command, becomes bit better and above than others, but it does not mean that he knows everything. Whether he is a Guru or a student, in fact Guru is also like a student. He helps his student to reach at the level of himself. Then they reciprocate the same.

Besides these factors, Deepika added that sometimes when teachers ask us to sing, something new comes out. Avantika also shared - ...in my examination, I had to make notations of given Bañdiśa.

Conscious Process of Music Making - Deepika shared her view that through conscious effort better things can be created. Conscious process is more rigorous and easy to articulate. Avantika, Ankita, and Pooram had the same view that one must be thorough with the shāstra of a rāga. Avantika said that although she never created her own genuine composition, but she made variations in notes of a particular rāga. She explicated the process:

...I have the lyrics. I read it carefully to understand the meaning. Accordingly, I select a rāga that suits to the meaning of the lyrics. Then I focus on those combinations of notes, if 


\section{Understanding Learners' Perspective on Creative Music Making}

they would be used, they might give impressions of other rāga. Then after, I practice the main combinations of notes and try to get myself absorbed into them. I start with lower octave. I take any two or three notes like $S, R$, and $G$ and try to make variations. Gradually I develop upon those variations that are new and sweet. Then I get feedback of my Guru whether it has maintained the nature of rāga.

Avantika further shared her view that continuously thinking upon the learned rāga and humming is also a kind of riāz. Unconsciously it is being processed in your mind. Ankita provided steps for making variations -

1. Concentrate on the notes to be used in a rāga,

2. Then on the notes not to be used,

3. Focus on the notes for nyās, vādi and samvādi,

4. Internalize the nature and method of the rāga,

5. Repeat the main combinations of notes, and

6. Then start creating tānas. Get feedback.

Moreover, Pooram said that we get feedback to improve further. We make rāga-based composition so that we can immerse ourselves in its emotion.

Findings suggest that music students start with a lyric that either has been selected by their own or has been offered by someone. Subsequently they try to understand the meaning of the words. They start rhyming. Through rhyming and reading the lyric repeatedly, they try to identify the intended meaning and emotion of the words. Then they look for the appropriate rāga and the minute details (as concentrating on the notes to be used or not to be used in a räga, focusing on the notes for nyās, vādi and samvādi, and internalizing is the nature and method of that rāga).

At this stage, music students write multiple combinations of rāga, and set their composition on an appropriate tāla. Afterward, musicians repeat the alternatives many times or sometime they just need to wait. Suddenly an original piece of composition emerges. It happens only through these repetitions. Then musicians put these pieces together: notes, tānas, etc. and complete the process of making composition. Lastly, they evaluate it critically. They look for critical comments from their colleagues, teachers/Guru and so on. 


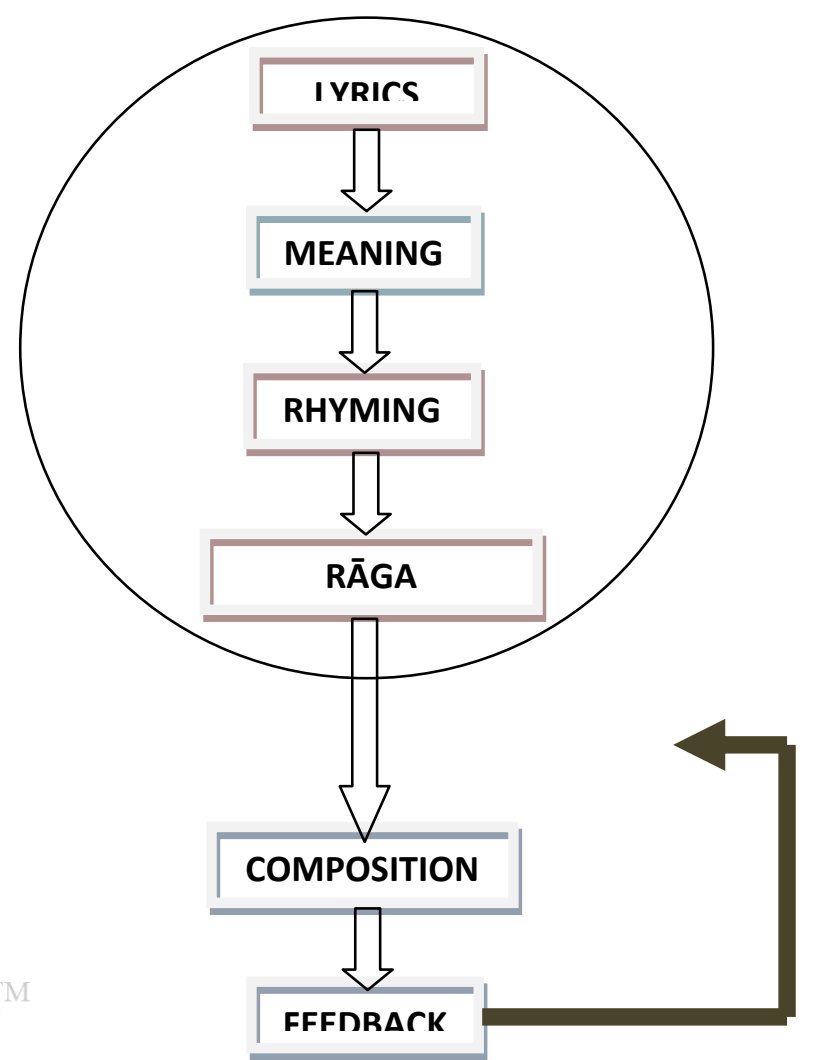

Figure 1: Conscious Music Making

In Figure 1, I have further tried to understand the process graphically. First four stages, from lyrics to rāga selection, reflect stages of preparation and exploration that provides a fertile ground for creativity to manifest. At this stage, repetition of composed notes, suddenly a new, genuine and appropriate tune emerges. During last two stages, composition and feedback, a creative composition takes its final shape that has gone through several modifications, syntheses, and verifications. What I could understand that the conscious process of music making broadly follows the stages propounded by Wallas (1926) and it closely goes with the Osborn's (1953) Seven-Step Model for creative thinking.

Natural Process of Music Making - A common notion could be observed through the responses of the participants that creation emerges naturally through these stimulating factors. All have shared that the process in which music emerges from some unknown sources may not be conveyed explicitly. However, few have tried. For natural creation, most of the participants shared this belief that one must be talented. As Pooram asserted:

If someone has inborn talent, he can create his own music. He does not require any training.

Therefore, as Anuragi suggested - do not wait for something special to appear. It happens naturally, while you are cycling, or doing riāz (Deepika). One must be vigilant when it pops out. So, what should one do? Anuragi said:

I always keep a pen and a notebook. Whenever some new Bandiśa or Dhun comes in my mind, I note it down. Otherwise, it will be disappeared. 


\section{Understanding Learners' Perspective on Creative Music Making}

Anuragi had this view that one must have complete knowledge of the particular rāga. Deepika averred further - I do not go for riāz with this thinking that I have to create something new. It emerges all of a sudden. She said that she starts by singing a rāga and meditating over the notes of that particular rāga. Urvashi further explained:

...as we are vocal students, every time there is something which goes on in our mind like our own Bhajan, or any rāga. While singing, some new combinations of notes appear which seems pleasant. You start liking your dhun. In the way, some new things emerge. I do not try it consciously. It comes naturally.

Namita recalled the process in detail -

Firstly dhun (tune) comes in mind. Consequently, Bol (words) emerges by itself. Then I set it with Tāla (rhythm) to make it more effective. Mood must be according to the rāga. If you don't have the knowledge of rāga, you can make it in any regional language. However, if it is rāga based then it will be more effective. It may also leave its effect on nonprofessionals. Because, notes used in a particular rāga, are not just notes. They jointly produce a Rasa.

Findings reveal that the process of natural egression initially follows different pathway. It starts with initiation through immediate surroundings and one's mood, which yields some emotions. And automatically dhun (tune) comes into the mind followed by words. Then it needs planning for the selection of appropriate words, tāla, ālāp, tāna, etc. Next step is to synthesize - putting them together. Then, musicians try to evaluate their composition through several repetitions of the composed piece and feedback. The process ends with writing the final composition.

Figure 2 depicts the natural or spontaneous process of music making. Dhun and words pop up in a particular mood that might be evoked through several stimulating factors as stated above. Then it is to be set on any tâla. Consequently, it is shaped into a complete composition. Now it is to be opened for feedback from friends, teachers, or other experts. The process ends with the final comprehensible and original composition. 


\section{Understanding Learners' Perspective on Creative Music Making}

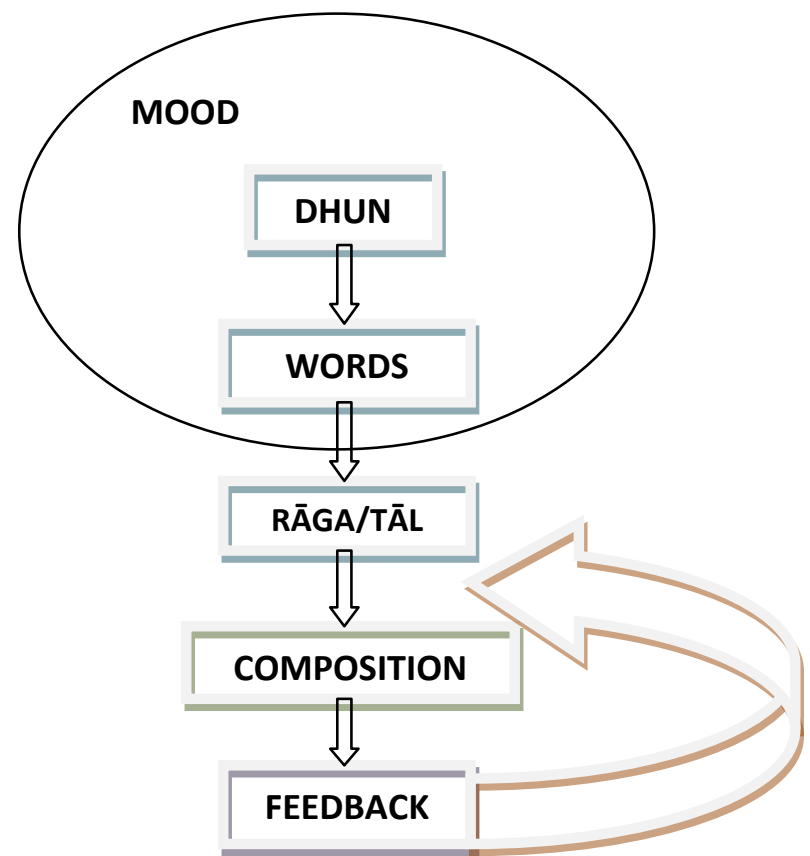

Figure 2: Natural Process of Music Making

\section{CONCLUDING COMMENTS}

Inspiration and visualization or imaginations were found very crucial for creativity. It may be the particular psychological state, occasion or situation when musicians get inspiration and visualize. Both creative processes follow different initial steps. Moreover, this contextual approach to understand creative music making confirms the most extensive model proposed by Webster (2002). According to this model a musician starts with particular product intension (e.g., composition or improvisation) that drive the process itself and the resulting products come from creative thinking. The process has certain effects of musicians' enabling skills (e.g., aptitude, conceptual understanding, etc.) and enabling personal as well as sociocultural conditions.

Upadhyay (2013) concludes that many of the musicians when they want to compose they prefer evening time and the fixed place of riāz. The time, the place and the immediate surroundings inspire them to visualize. They think over the rāga repeatedly and contemplates whether it appropriately suits the song they have and, what could be more in tune with the mood of the composition. Mittelstaedt (1995) rightly pointed that the composition or creation of the piece will be dull and uninteresting if inspiration is absent.

Present work was a rare endeavour in the area of creative music making in Hindustani music tradition that captured the students' perspective. It opened a new vista for future research in this direction. As this study has had confined to only music students (vocal music) belonging to Hindustani music tradition, future studies might analyse the professionals' perspective as well in order to develop a complete model of creative music making. Students and professionals of different areas of music (i.e., vocal, dance and instruments) could be considered at the same time to further strengthen the model. Future research in the area of creativity in music might also be designed along the lines of comparative analysis: a comparative analysis between two groups: one representing Carnatic music tradition and the other Hindustani music. Case studies, focusgroup interviews, and classroom observations might have yielded findings that are more robust. 


\section{REFERENCES}

1. Arasteh, A. R., \& Arasteh, J. D. (1976). Creativity and human development: An interpretative and annotated bibliography. New York: Schenkman.

2. Arieti, S. 1976. Creativity. The Magic Synthesis. New York: Basic Books.

3. Bandopadhyay, S. (1977/1995). The origin of Rāga. New Delhi: Munshiram Manoharlal Publishers Pvt. Ltd.

4. Barrett, M. (2003). Musical children, musical lives, musical worlds. In S. Wright (Ed.), Children, meaning-making and the arts (pp. 63-85). Frenchs Forest, NSW: Person Prentice Hall.

5. Barron, F. (1988). Putting creativity to work. In R.J. Sternberg (Ed.), The Nature of Creativity. Cambridge, England: Cambridge University Press.

6. Beghetto, R. A., \& Kaufman, J. C. (2007). Toward a broader conception of creativity: A case for mini-c creativity. Psychology of Aesthetics, Creativity, and the Arts, 1, 73-79.

7. Bhawuk, D. P. S. (2003). Culture's influence on creativity: The case of Indian spirituality. International Journal of Intercultural Relations, 27, 1-22.

8. Dhar, S. (2005). Raga 'n Josh: Stories from a Musical Life. UK: Hachette

9. Hickey, M. (2001). An application of Amabile's consensual assessment technique for rating the creativity of children's musical compositions, Journal of Research in Music Education, 49 (3), 234-244.

10. Hickey, M. (2002). Connecting perspectives on music composition for children. Paper presented at the 25th Biennial Conference in Music Education, 19 August, Bergen, Norway.

11. Kakar, S., \& Kakar, K. (2007). The Indians: Portrait of a people. New Delhi: Penguin Books.

12. Kaufman, J.C., Lee, J., Baer, J., \& Lee, S. (2007). Captions, consistency, creativity, and the consensual assessment techniques: New evidence of validity. Thinking Skills and Creativity, 2, 96-106.

13. Keating, D. P. (1980). Four faces of creativity. Gifted Child Quarterly, 24, 56-61.

14. Lau, M. W. C. (2006). Strategies kindergarten teachers use to enhance children's musical creativity: Case studies of three Hong Kong teachers. Unpublished $\mathrm{PhD}$ thesis, Center for Learning Innovation, Queensland university of Technology, Hong Kong.

15. Lubart, T. I. (1999). Creativity across cultures. In R. J. Sternberg (Ed.), Handbook of creativity (pp. 339-350). Cambridge: Cambridge University Press.

16. Majumdar, A. (2004). Bhimsen Joshi: A passion for music. Delhi: Rupa publications India Pvt. Ltd.

17. Mansukhani, G. S. (1982). Indian classical music and Sikh kirtan. New York.

18. Meer, W. V. D. (1980). Hindustani music in the 20th century. The Hague: Martinus Nijhoff Publishers.

19. Mittelstaedt, J. (1995). Steps in the creative process. OMTA. 
20. Newman, T. U. (2008). The creative process of music composition: A qualitative selfstudy. Unpublished dissertation, New York university, New York.

21. Odena, O. (2002, September). Using videotaped extracts of lessons during interviews to facilitate the eliciting of teachers' thinking: An example with music schoolteachers' views of creativity. Paper presented at the European Educational Research Association Annual Conference, University of Lisbon, Portugal. Retrieved November 2007, from http://www.leeds.ac.uk/educol/documents/ 00002206.htm

22. Osborn, A. (1953). Applied Imagination. New York: Charles Scribner.

23. Panda, M. (2011). Cultural Construction of Creativity: Dualism and Beyond. In M. Cornelissen, G. Mishra, \& S. Verma (Eds.), Psychology: The Indian tradition. New Delhi: Pearson

24. Plsek, P. E. (1996). Working Paper: Models for the Creative Process. Retrieved November 2010 from http://www.directedcreativity.com/pages/WPModels.html

25. Rhodes, M. (1961). An analysis of creativity. Phi Delta Kappa, 42, 305-310

26. Rossman, J. (1931). The Psychology of the Inventor. Washington DC: Inventor's Publishing.

27. Running, D. G. (2008). Creativity research in music education: A review (1980-2005). Application of Research in Music Education 27(1), 41-48.

28. Sloboda, J. (1985). The musical mind, the cognitive psychology of music. Oxford: Oxford University Press.

29. Torrance, E. P. (1988). The nature of creativity as manifest in its testing. In Sternberg, R. J. (Ed.), The nature of creativity. Cambridge, England: Cambridge Univ. Press.

30. Upadhyay, D. K. (2013). Psychosocial dispositions of creative musicians. Unpublished PhD thesis, Center for Advanced Studies, Department of Psychology, University of Allahabad, India.

31. Vinacke, WE (1953). The psychology of thinking. New York: McGraw Hill.

32. Wallas, G. (1926). The art of thought. London: C. A. Watts.

33. Weber, A. (1976). Lectures on Indian literature. Retrieved 11 April 2009 from http://www.michaelwheelerstudios.com/uploads/7/1/4/6/7146403/indian_classical_music __sikh_kirtan.pdf

34. Webster, P. (2002). Creative thinking in music: Advancing a model. In T Sullivan and L Willingham (Eds.), Creativity and music education, (pp. 16-33). Canadian Music Educators' Association, Edmonton, AB.

35. Wertheimer, M (1945). Productive Thinking. New York: Harper.

36. Wright, S. (2003). The arts, young children and learning. Bostan, MA: Allyn and Bacon. 